\title{
PENERAPAN AUDIO VISUAL TERHADAP PENGENALAN BAHASA INGGRIS DI KELOMPOK A1 RA AN-NUR NURUL AULIA
}

\author{
Eti Nurhayati ${ }^{1}$, Ema Aprianti $^{2}$ \\ RA An-NurNurulAulia, Cimahi ${ }^{1}$, PG PAUD IKIP Siliwangi, Cimahi ${ }^{2}$ \\ eti.nurhayati0879@gmail.com ${ }^{1}$, emaaprianti88@gmail.com²
}

\begin{abstract}
One of the practical medium in the introduction of English in children is audio visual. In accordance with the principle of learning in pre-school children is to play while learning, learning English must be presented with play, fun, and use the media of interest. With the advancement of technology in education, especially teaching, people think one step ahead. With the hope of early childhood it is easier to respond, understand, motivate and add vocabulary of the International Language of the child. The formulation of the problem "How The Implementation Of Audio Visual To Introduction Of English In AA Group RA An Nur Nurul Aulia". This study aims to determine the improvement and understanding of English vocabulary through "Audio Visual Application To Introduction of English Language in Group A1 RA An Nur Nurul Aulia". The method used in this research is qualitative method with analytical descriptive. Research data collected by using instrument in the form of interview and observation guidance. The results obtained observations got satisfactory results. With audio visual audio in English introduction can improve responsiveness, understand, motivate and add vocabulary of children. Research location at RA An Nur Nurul Aulia Jl. Sukarasa No. 26 RT 04 RW 11 Kelurahan Citeureup North Cimahi Subdistrict Cimahi City.
\end{abstract}

\section{Keywords: Audio visual, English}

\begin{abstract}
Abstrak
Salah satu media yang praktis dalam pengenalan Bahasa Inggris pada anak yaitu audio visual. Sesuai dengan prinsip belajar pada anakpra sekolah yaitu bermain sambil belajar, pembelajaran bahasa Inggris pun harus disajikan dengan bermain, menyenangkan, serta menggunakan media yang menarik. Dengan kemajuan teknologi dalam pendidikan, khususnya pengajaran, manusia berfikir selangkah lebih maju. Dengan harapan anak-anak usia dini semakin mudah untuk merespon, memahami, memotivasi dan menambah kosakata Bahasa Internasional anak. Rumusan masalahnya " Bagaimana Penerapan Audio Visual terhadap Pengenalan Bahasa Inggris Di kelompok A1 RA An-Nur Nurul Aulia".Penelitianinibertujuan untuk mengetahui peningkatan dan pemahaman kosakata bahasa Inggris melalui "Penerapan Audio Visual Terhadap Pengenalan Bahasa Inggris di Kelompok A1 RA An-Nur Nurul Aulia". Metode yang digunakan dalam penelitian ini adalah metode kualitatif dengan deskriptik analitis. Data penelitian dikumpulkan dengan menggunakan instrument berupapedoanwawancara dan pedoman observasi. Hasil yang diperoleh pengamatan mendapat hasil yang memuaskan. Dengan penerpan audio visual dalam pengenalan Bahasa Inggris dapat meningkatkan respon, memahami, memotivasi dan menambah kosakata anak. Lokasi penelitian di RA An-Nur Nurul Aulia Jl. Sukarasa No. 26 RT 04 RW 11 Kelurahan Citeureup Kecamatan Cimahi Utara Kota Cimahi.
\end{abstract}

Kata Kunci : Audio visual, Bahasa Inggris 


\section{PENDAHULUAN}

Pada usia dini anak sedang mengalami perkembangan otak yang sangat pesat. Perkembangan otak mereka sangat banyak ditentukan oleh beragam stimulus, nutrisi, dan juga gen bawaan mereka. Salah satu upaya memanfaatkan perkembangan otak anak yang sangat pesat saat ini adalah dengan memberikan stimulus Bahasa Inggris bagi anak. Stimulasi Bahasa Inggris sangat penting bagi perkembangan sel-sel otak yang akhirnya akan berdampak pada perkembangan kognitif anak usia dini.Menurut Berk (Sujiono, 2012. Hlm. 6)Anak Usia Dini adalah sosok individu yang sedang menjalani proses perkembangan dengan pesat dan fundamental bagi kehidupan selanjutnya. Anak usia dini pada usia 0-8 tahun. Pada masa ini proses pertumbuhan dan perkembangan dalam berbagai aspek sedang mengalami masa yang cepat dalam rentang perkembangan hidup manusia.

Pengenalan kosakatabahasa Inggris yang masih kurang pada anak usia pra sekolah dikarenakan latar belakang sekolah yang kurang mendukung pengenalan bahasa Inggris, pembelajaran yang kurang menarik, pemilihan bahan ajar bahasa Inggris yang kurang tepat di sekolah, komunikasi yang kurang hangat antara guru dan siswa, serta pengunaan media yang kurang varaitif dalam pengenalan bahasa Inggris pada anak usia pra sekolah.

Sesuai dengan prinsip belajar pada anak usia pra sekolah yaitu bermain sambil belajar, pembelajaran bahasa Inggris pun harus disajikan dengan bermain, menyenangkan, serta menggunakan media yang menarik. Dengan peningkatan teknologi dalam pendidikan, khususnya pelajaran, manusia berfikir selangkah lebih maju.
Dengan melibatkan penglihatan dan pendengaran dapat menambah kosakata bahasa Inggris dan dapat lebih mudah difahami oleh anak. Dengan pemanfaatan audio visual suasana belajar juga lebih asyik sehingga anakanak tidak merasa bosan dan lebih semangat untuk mengikuti pengenalan bahasa Inggris. Pengucapan bahasa Inggris (Pronouncation) juga akan lebih diterima karena anak mendengar langsung dari media tersebut. Oleh karena itu dengan pemanfaatan media audio visual ini diharapkan dapat meningkatkan pembendaharaan kata bahasa Inggris anak.

\section{KAJIAN PUSTAKA}

A. Konsep Pendidikan Anak Usia Dini

1. Pengertian Pendidikan Anak Usia Dini

Pendidikan pra sekolah yaitu suatu proses stimulasi tumbuh kembangnya anak usia lahir hingga enam tahun secara menyeluruh, yang mencakup aspek motorik, dengan memberikan stimulasi bagi perkembangan jasmani, rohani (moral dan spiritual), motorik, akal pikir, dan sosial emosional agar anak dapat tumbuh dan berkembang secara optimal.

2. Hakikat Anak Usia Dini

Anak usia dini adalah sosok yang sedang menjalani suatu perkembangan dengan pesat dan fundamental bagi kehidupan selanjutnya. Anak usia dini berada pada rentang usia 0-8 tahun (Www.naeyc.org, n.d.) Pada masa ini proses pertumbuhan dan pekembangan dalam berbagai aspek sedang mengalami masa yang cepat dalam rentang perkembangan manusia. (Sujiono, 2012. Hlm. 6)Proses pembelajaran sebagai bentuk perlakuan yang diberikan pada anak harus mempraktikan karakteristik yang dimiliki setiap tahapan perkembangan anak 


\section{JURNAL CERIA}

ISSN : 2614-6347 (Print) 2614-4107 (Online)

Vol.1_No.2 L Maret 2018

3. Tujuan Pendidikan Anak Usia Dini

Adalah untuk menstimulasi pengetahuan dan pemahaman orang tua dan pendidik serta pihak-pihak pendidikan dan perkembangan anak usia dini

\section{B. Konsep Media}

1. Pengertian Media Pembelajaran

Media berasal dari bahasa latin medius yang berarti 'tengah', 'perantara' atau 'pengantar'. Dalam bahasa Arab, media adalah perantara atau pengantar pesan dari pengirim kepada penerima pesan.

Gerlach \& Ely (Arsyad, 2017. Hlm.3)mengatakan bahwa media apabila dipahami secara garis besar adalah manusia, materi, atau kejadian yang membangun kondisi yang membuat siswa mendapat pengetahuan, keterampilan.

2. Pengertian Media Audio Visual Media audio visual merupakan seperangkat alat yang dapat memproyeksikan gambar bergerak dan bersuara(Wati, 2016. Hlm. 44). Panduan antara gambar dan suara pada media audio visual akan membentuk sebuah karakter yang sama dengan obyek aslinya. Alat-alat kategori media audio visual adalah televisi, video atau VCD, serta sound dan film.

3. Karakteristik Media pembelajaran berbasis Audio Visual

Media audio visual dapat menunjukan objek kontekstual. Perencanaan yang baik dalam memakai media audio visual akan memproses komunikasi atau pembelajaran menjadi lebih efektif. Pembelajaran yang menggunakan media audio visual, bercirikan pemakaian hardware selama proses pembelajaran.

\section{Konsep Bahasa Inggris}

1. Pengertian Bahasa Inggris

Bahasa Inggris (English) merupakan bahasa resmi dari negara-negara persemakmuran dan dipahami, dipergunakan

secara meluas(Http://infopengertian.biz/penger tian-bahasa-inggris-sejarah-serta-kosakata-terbaru.html, n.d.).Bahasa Inggris dipergunakan di negara-negara di dunia dibanding bahasa yang lain.

2. Pentingnya Pengenalan Bahasa Inggris untuk Anak Pra Sekolah

Dari beragam bahasa yang ada di dunia, dewasa ini Bahasa Inggris merupakan bahasa asing yang menjadi primadona untuk diajarkan kepada anak usia dini. Bahasa Inggris dianggap penting untuk kesuksesan anak dimasa depan serta dipertimbangkan sebagai Bahasa kunci untuk menguasai ilmu pengetahuan yang perlu dipelajarai oleh orang Indonesia. Mulai dari tahun 60'an hingga sekarang.

\section{METODE PENELITIAN}

\section{A. Metode Penelitian}

Metode pada penelitian ini adalah metode pendekatan kualitatif dengan deskriptif analisis dengan menggunakan tekhnik observasi dan dokumentasi.

Dalam metode penelitian, deskriptif peneliti tidak hanya memberikan gambaran terhadap fenomenafenomena saja, jugamenerangkan hubungan, membuat prediksi, serta mendapatkan makna dan implikasi dari masalah yang logis dipecahkan. Menurut Whitney (Nazir, 2005. Hlm. 54)metode deskriftif adalah pencarian fakta-fakta dengan interprestasi yang tepat.

Peneliti memakai pendekatan kualitatif agar dapat memahami dan mengungkapkan secara mendalam mengenai penerapan audio visual dalam pembelajaran bahasa Inggris.

\section{B. Teknik Pengumpulan Data}

Teknik pengambilan data yang dilaksanakan dalam penelitian ini sebagai berikut :

1. Observasi

2. Wawancara 
3. Studi Dokumentasi

4. Studi Literatur

\section{Instrument Penelitian}

Pengumpulan data sebuah penelitian yang dilakukan berbagai metodemetode penelitian seperti, observasi, wawancara, studi dokumentasi dan studi literatur memerlukan alat bantu seperti instrument. Instrument yang dimaksud adalah telepon genggam, pensil, ballpoint, buku. Telepon genggam digunakan sebagai media untuk mendokumentasikan foto.

\section{Subjek Penelitian}

Subyek penelitian adalah berbagai karakteristik yang terlibat dalam pengealan Bahasa Inggris yang terdiri dari 14 siswa dan satu pendidik.

Lokasi penelitian dilaksanakan di RA An-Nur Nurul Aulia Kelurahan Citeureup Kecamatan Cimahi Utara. Adapun subjek penelitian adalah siswasiswi kelompok A1 RA An-Nur Nurul Aulia Citeureup Cimahi pada semester II tahun ajaran 2017-2018. Jumlah siswa 14 (empat belas) orang, yang terdiri dari 8 orang laki-laki dan 6 orang perempuan.

\section{E. Teknik Pengolahan Dan Analisis Data}

Dalam penelitian kualitatif, data didapat dari berbagai sumber, dengan pengumpulan data yang bermacammacam (triangulasi), dan dilakukan secara terus menerus sampai datanya jenuh. Data yang diperoleh adalah kualitatif, teknik analisis data yang dipakai belum ada pola yang jelas. Karena itu sering mengalami kesulitan dalam melakukan analisis. Selanjutnya Nasution (Sugiyono, 2010. Hlm. 244)menyatakan "Melakukan analisis adalah pekerjaan yang sulit, memerlukan kerja keras. Analisis memerlukan daya kreatif serta kemampuan intelektual yang tinggi.

\section{F. Langkah-Langkah Penelitian \\ Menurut(Moleong, 2002. Hlm.} 127)bahwa tahapan yang dilakukan dalam penelitian ini ada empat tahap, yaitu:

1. Tahap Pra Lapangan

2. Tahap Pelaksanaan

3. Tahap Analisis Data

4. Tahap Pelaporan

\section{HASIL PENELITIAN DAN PEMBAHASAN}

\section{A. Profil Lokasi Penelitian}

1. Identitas Lembaga

Nama sekolah An-Nur dengan No. izin operasional 101232770004 yang beralamat di Jl. Sukarasa No. 26 RT 04 RW 11 Kelurahan Citeureup Kecamatan Cimahi Utara Kota Cimahi Provinsi Jawa Barat Kode Pos 40512. Nama yayasannya adalah Yayasan Nurul Aulia tahun berdiri 1997 dengan status tanah hak ilik perorangan an Bapak H. Aga Sumarga (Alm)

\section{B. Deskripsi dan Analsis Hasil Penelitian}

1. Perencanaan Penerapan Audio Visual Terhadap Pengenalan Bahasa Inggris di Kelompok A1 RA An-Nur Nurul Aulia

Langkah pertama dibuat terlebih dahulu rencana pembelajaran oleh guru khusus Bahasa Inggris yang disesuaikan dengan tema yaitu tema tempat umum dengan sub tema tempat rekreasi. Kemudian mempersiapkan ruangan tertutup sehingga cahaya yang masuk tidak terlalu menganggu pemutaran media. Selanjutnya mempersiapkan software dan hardware yang akan dipakai dalam menunjang proses pembelajaran. Memastikan software yang dipakai dalam menjelaskan materi sesuai untuk disimak oleh peserta didik. Menyiapkan juga pertanyaanpertanyaan yang berkaitan dengan pembelajaran. Sebelum memulai kita 


\section{JURNAL CERIA}

ISSN : 2614-6347 (Print) 2614-4107 (Online)

Vol.1_No.2 L Maret 2018

pastikan juga posisi duduk siswa dalam menyimak video apakah nyaman atau tidak. Lembar kerja anak dan penilaian anakpun dipersiapkan.

2. Pelaksanaan Penerapan Audio Visual Terhadap Pembelajaran Bahasa Inggris di Kelompok A1 RA An-Nur Nurul Aulia

Lamanya waktu yang digunakan proses belajar yaitu hari Selasa dimulai pukul 09.00-10.00 WIB. Dengan tahapan pelaksanaan pembelajaran disusun sebagai berikut :

1) Perencanaan (Plan)

2) Kegiatan awal (Pre-activities)

3) Kegiatan Inti (main-activities)

4) Kegiatan akhir (post-activities)

\section{Pembahasan Hasil Penelitian}

1. Perencanaan Penerapan Audio Visual Terhadap Pengenalan Bahasa Inggris di Kelompok A1 RA An-Nur Nurul Aulia

Pada perencanaan pembelajaran untuk memakai media audio visual disesuaikan dengan tema. Yang dipersiapkan untuk penerapan audio visual dalam pengenalan Bahasa Inggris

a. Membuat rencana pembelajaran (lesson plan),

b. Memahami terlebih dahulu program yang akan ditampilkan pada siswa, agar lebih diketahui secara pasti materi apa yang akan ditampilkan jadi apabila terdapat kekurangan dapat diketahui terlebih dahulu.

c. Mempelajari dahulu kata-kata atau istilah yang perlu disajikan kepada siswa sebelum menyaksikan program.

d. Menyediaka peralatan yang akan dipergunakan agar dalam pelaksanaannya nanti tidak terburuburu dan tidak perlu mencari-cari lagi.

2. Pelaksanaan Penerapan Audio Visual Terhadap Pengenalan
Bahasa Inggris di Kelompok 0A1

RA An-Nur Nurul Aulia

Pada pelaksanaannya media audio visual ini sangat memudahkan guru karena tidak memerlukan banyak aktivitas dalam proses kegiatan pembelajaran. Sebelum pemutaran video guru dan anak membuat aturan main dulu, kemudian anak diberikan penjelasan tentang materi yang akan disampaikan.

Yang perlu di ketahui dalam mengajar menggunakan media video antara lain:

a. Ruang penyaji

b. Peralatan yang dipergunakan

c. Tata letak peralatan

d. Langkah-langkah pelaksanaan

3. Hasil Penerapan Audio Visual Terhadap Pembelajaran Bahasa Inggris di Kelompok A1 RA AnNur Nurul Aulia

Hasil penerapan audio visual terhadap pengenalan Bahasa Inggris di kelompok A1 RA An-Nur Nurul Aulia dapat terlihat melalui analisis hasil pembelajaran dengan beberapa indikator pertanyaan yang dijadikan bahan observasi.

a. Hasil observasi menunjukan bahwa sebagian besar respon siswa/I kelas A1 mengalami perubahan ketika diterapkannya media audio visual sebagai media pembelajaran, anak senang dengan pembelajaran Bahasa Inggris.

b. Perhatian anak semakin terfokus kepada pembelajaran dan anak tertarik dengan pembelajaran Bahasa Inggris.

c. Hasil observasi menunjukan siswa/I kelas A1 memiliki motivasi belajar yang tinggi, namun ada 2 orang yang masih belum memiliki motivasi yang tinggi yaitu ananda $F$ dan ananda $\mathrm{S}$ yang masih perlu stimulasi untuk itu ananda masih memerlukan pendidik untuk memberikan proses pembelajaran yang lebih menarik lagi. 
d. Hasil observasi menunjukkan anak mampu menambah kosakata seperti halnya ananda $\mathrm{Ar}, \mathrm{Al}, \mathrm{Au}, \mathrm{I}, \mathrm{D}, \mathrm{Q}$, As, Aq, T, dan $\mathrm{N}$ sedangkan ananda $\mathrm{A}, \mathrm{F}$ dan $\mathrm{S}$ masih harus distimulasi lagi.

e. Hasil observasi menunjukan siswa/I kelas A1 dapat mendengar dan memahami ketika guru sedang bercerita..

f. Hasil observasi menunjukan dari 14 siswa ada 10 orang yang mampu mengucapkan kembali 5 kata yang baru didengar yaitu ananda Aq, As, Ar, D, Q, T, Au, Al, N, I dan 4 orang lagi yang masih harus distimulasi yaitu ananda F, S, A dan W.

g. Hasil observasi menunjukan 11 siswa mampu menyebutkan lambang huruf secara berurutan yaitu ananda Aq, As, Ar, D, Q, T, $\mathrm{Au}, \mathrm{Al}, \mathrm{N}, \mathrm{I}$ dan $\mathrm{W}$, sisanya 3 siswa yaitu F, A dan $\mathrm{S}$ masih harus distimulasi.

h. Hasil observasi menunjukan siswa/I kelas A1 dapat menghasilkan suatu karya.

\section{KESIMPULAN}

Berdasarkan hasil pembahasan mengenai penerapan audio visual terhadap Pengenalan Bahasa Inggris di kelompok A1 RA An-Nur Nurul Aulia, maka dapat disimpulkan dari pertanyaan penelitian sebagai berikut :

1. Perencanaan pembelajaran adalah hal yang wajib dikerjakan dan disediakan guna tercapainya kegiatan belajar mengajar yang lancar.

2. Pelaksanaan penerapan audio visual terhadap pembelajaran Bahasa Inggris ditempuh melalui tahaptahap pelaksanaan yang sederhana mudah diikuti oleh anak-anak, yaitu melalui tahap-tahapan menyusun rencana pembelajaran yang dibagi kedalam tiga tahap yakni pembukaan (pre- activities), inti (main activities) dan penutup (post-activities).

3. Hasil penelitian penerapan media audio visual terhadap pembelajaran Bahasa Inggris, respon anak meningkat, peningkatan perhatian anak, meningkatnya motivasi belajar anak, hasil belajar lebih bermakna, memahami dan menunjukan kemampuan bahasa reseptif, memahami dan menunjukan kemampuan bahasa ekspresif, mengenal keaksaraan awal, menghasilkan sebuah karya, membantu memudahkan belajar bagi anak dan memudahkan mengajar bagi guru, memberikan pengalaman lebih nyata.

\section{UCAPAN TERIMA KASIH}

Penulis menyadari bahwa terwujudnya jurnal ini berkat bantuan dan bimbingan dari berbagai pihak. Sudah sepantasnya penulis mengucapkan terima kasih dan penghargaan yang sebesar-besarnya kepada :

1. Bapak Dr. H. Heris Hendriana, M.Pd selaku Rektor IKIP Siliwangi.

2. Bapak Dr. Ramdhan Witarsa, M.Pd selaku Dekan Fakultas Ilmu Pendidikan (FIP) IKIP Siliwangi.

3. Ibu Prof. Dr. Hj. Arifah A. Riyanto, M.Pd selaku Ketua Program Studi PG PAUD IKIP Siliwangi.

4. Ibu Ema Aprianti, M.Pd selaku pembimbing yang telah memberikan arahan yang maksimal dalam penyusunan jurnal ini.

5. Ibunda dan ayahahanda tercinta (Ibu Osih Ronasih dan Bapak Omon (Alm)) yang senantiasa mencurahkan do'anya dengan penuh kasih sayang yang tulus dan ikhlas.

6. Suami tersayang Yadi Setiadi yang selalu memberikan dukungan moril serta materil dengan ikhlas. 


\section{JURNAL CERIA}

ISSN : 2614-6347 (Print) 2614-4107 (Online)

Vol.1 No.2 Laret 2018

10. Putra-putraku (Ilham Arif Maulana dan Muhammad Rifa Baihaqi) tersayang yang menjadi penyemangat sejak awal kuliah sampai selesai.

12. Seluruh dosen IKIP Siliwangi, yang telah membekali penulis sejak awal perkuliahan sampai tugas akhir selesai.

13. Teman-teman mahasiswa program studi senantiasa kompak dalam menghadapi segala rintangan baik secara pribadi maupun bersamasama.

\section{DAFTAR PUSTAKA}

Arsyad, A. (2017). Media

Pembelajaran. Jakarta: PT Raja

Grafidno Persada.

Http://infopengertian.biz/pengertianbahasa-inggris-sejarah-serta-kosakata-terbaru.html. (n.d.). No Title.

Moleong, J. L. (2002). Metode Penelitian Kualitatif. Bandung. PT Remaja Rosda Karya.

Nazir, M. (2005). Metode Penelitian. Jakarta: Ghalia Indonesia.

Sugiyono. (2010). Metode Penelitian Pendidikan. Bandung: Alfabeta.

Sujiono, Y. N. (2012). Konsep Dasar Pendidikan Anak Usia Dini. Jakarta: Indeks.

Wati, E. R. (2016). Ragam Media Pembelajaran. Kata Pena.

Www.naeyc.org, H. (n.d.). No Title.

Arsyad, A. (2017). Media Pembelajaran. Jakarta: PT Raja Grafidno Persada.

Http://infopengertian.biz/pengertianbahasa-inggris-sejarah-serta-kosakata-terbaru.html. (n.d.). No Title.

Moleong, J. L. (2002). Metode Penelitian Kualitatif. Bandung. PT Remaja Rosda Karya.

Nazir, M. (2005). Metode Penelitian. Jakarta: Ghalia Indonesia.

Sugiyono. (2010). Metode Penelitian Pendidikan. Bandung: Alfabeta.

Sujiono, Y. N. (2012). Konsep Dasar Pendidikan Anak Usia Dini. Jakarta: 